\title{
¿QUE HA PASADO CON LA PINTURA?
}

\section{Por Ida Rodriguez Prampolini}

La evolución de las artes plásticas ha producido últimamente una serie de cambios novedosos; uno de éstos es el hecho innegable de que la pintura ya no es la que encabeza la marcha de las artes plásticas en la actualidad como lo hizo desde la segunda mitad del siglo xix hasta las primeras décadas del $\mathbf{x x}$.

El artista actual se ha atareado en la lucha por investigar las dimensiones del espacio y del tiempo para aplicarlas, incluso, al complejo urbano. Las metas principales del momento han reducido considerablemente la importancia del cuadro y merecen un estudio las preguntas: ¿qué pasa con la pintura? ¿Tiene alguna validez el cuadro de caballete?

Como el panorama que ofrecen las artes es muy complejo, quisiera en estas cortas consideraciones ocuparme de las lineas generales que han desarrollado los artistas dentro del marco de un lienzo y demostrar que, a pesar de la evidente confusión, existen ciertos hilos de continuidad que, no obstante las apariencias contrarias, se han ido desarrollando a lo largo de la historia de la pintura desde su liberación académica -impresionismo- como un gran circulo que parece, por fin, haber cerrado y unido sus extremos.

Desde que los teóricos del "arte por el arte" -Musset, Gautier, Mérimée, Schiller, Schelling, Shelley, Keats y tantos otros- desarrollaron sus teorías para independizar el arte de preocupaciones utilitarias, sociales, políticas y religiosas y lo levantaron sobre el pedestal de la independencia, la pintura no ha podido escapar de ese círculo cerrado de las preocupaciones puramente estéticas. La arquitectura, entre las artes es la que más dificilmente podia desvincularse de las funciones utilitarias; la escultura ligada al monumento conmemorativo o a la arquitectura tardó unos años más en desatarse y volverse autónoma. Era la pințura la que más fácilmente se prestaba a especulaciones desinteresadas y puramente plásticas y fue, justo bajo el postulado del "arte por el arte" como pudo dar la variación de ricos frutos que hemos visto aparecer en los últimos cien años de exaltación de la belleza o de su contrapartida la anti-belleza, que en definitiva responde y se mueve bajo idéntica base.

No quisiera hablar en este ensayo de los enriquecimientos y cambios que alteraron el concepto del cuadro sostenido en la pared con un clavo 
-collage, relieve, ensamblado, productos de las máquinas que pintan, medios mixtos, etcétera, toda la gama de nuevos tipos de arte que han venido a romper las divisiones tradicionales de las ramas de las Bellas Artes-- sino quiero limitarme al concepto tradicional de una superficic pintada y encerrada en un marco que se llama "pintura".

La pregunta ¿qué ha pasado con la pintura?, sólo es menester enfocarla después del movimiento Dada. Dada, al declarar que "se acabó el arte" cuestionó fundamentalmente la validez de la pintura que en ese momento era la rama más sobresaliente de la vanguardia artística. Dada declaró el desorden total y por lo tanto liquidó para siempre el orden estético en que la pintura se basaba. Sin embargo, a pesar de que Dada asesinó la pintura como su bandera fue la contradicción y el absurdo, los dadaistas realizaron una serie de exposiciones donde consagraron a artistas ya connotados y dieron absoluto sostén a la pintura abstracta que comenzaba a brotar con fuerza por esos años. Puede decirse que el arte contemporáneo con su nuevo potencial de anti-estética que lo caracteriza, nace con Dada. Los movimientos anteriores a este singular cambio y ruptura siguen, a pesar de las múltiples transformaciones, ligados a la actitud estetizante de la gran tradición artística del siglo xIX. Cada movimiento surgido después de las innovaciones luminosas de los impresionistas, eran búsquedas con banderas distintas por expresar bellamente la realidad, aunque ésta fuera conceptual como en el caso del cubismo o distorcionada y trágica como en el de los expresionistas.

Dada marca un punto a la tradición, una ruptura fundamental y un llamado a una nueva conciencia artística que sigue viva en la actualidad. Por lo tanto es importante comenzar el balance de la pintura en y desde el momento en que surge el grito demoledor del "Cabaret Voltaire".

Aparte de la pintura de los movimientos anteriores a 1916 -impresionismo, puntillismo, expresionismo, cubismo y futurismo- y la influencia de los grandes artistas de fin de siglo, lecciones que aún seguían en vigor, nacen varias invenciones trascendentales. Por una parte aparece la abstracción que brota con ciertas modalidades pero con unísono vigor en varias partes del mundo. El terreno se encontraba preparado por la inmediata tradición y la abstracción se presenta como inevitable consecuencia. El expresionismo lírico, musical y psicológico de Wassily Kandinsky contrasta con la abstracción geométrica y restringida del grupo "De Stijl" encabezado principalmente por Piet Mondrian. El orfismo purista de Robert Delaunay, las abstracciones biomórficas de Sophie Täuber-Arp y Jean Arp y la obra no-figurativa de algunos artistas menos 
reconocidos, marcan el comienzo de la ruta pictórica más importante de nuestro siglo. Pero no cabe duda que estudiada en perspectiva la historia del arte desde nuestra situación actual, la postura que aparece como una de las más radicales y rotundas, es la del suprematista ruso Kasimir Malevich y su mundo de la no-representación. La obra y los conceptos de Malevich llevan a la pintura a un desierto después de pasar por una base geométrica donde reinan el rectángulo, el círculo, el triángulo y la cruz, reducción de su concepto estético. Malevich, después de su cuadro revolucionario de 1913 (el cuadrado negro sobre fondo blanco) lleva su tesis a un extremo aún más esencial, pintando un cuadrado blanco sobre fondo blanco, postulando la pureza y alcanzando, por otra vía, el extremo místico que Kandinsky había logrado con el color. EI artista, afirma este primer autor de la pintura monocromática, como idolo de la sociedad pertenece ya al pasado y las Bellas Artes están puestas en entredicho: la media noche del arte ha sonado y concluye: El arte ha llegado a ser algo a sabiendas tan fácil que el artista resulta un ser superfluo.

Las teorías de Malevich, la búsqueda de un lenguaje universal planteado por el grupo De Stijl y sus leyes del balance asimétrico o equilibrio dinámico basadas en el ángulo recto y los colores primarios, encuentros que ayudaron a cristalizar las enseñanzas de la "Bauhaus", influyeron en una serie de artistas que, durante el periodo entre las dos grandes guerras, realizan una obra de formas cerradas o concretas ligadas a la geometría. La necesidad de recrear el mundo después de la primera guerra y construir el andamiaje de una nueva colectividad, opusieron las siluetas geometrizantes compuestas en infinitas variaciones, a los intelectualizados juegos del subconsciente de los surrealistas que postulan el absurdo y la fantasía y que constituyen el polo opuesto de la producción pictórica del mismo periodo.

Alberto Magnelli, Frank Kupka, los esposos Arp, Edgar Pillet, Auguste Herbin, Jean Leppien, César Domela, Ben Nicholson, Victor Passmore, Félix del Marle y muchos otros, realizan una obra donde los colores brillantes y planos están contenidos en formas cerradas y la sensibilidad, voluntariamente restringida, es la que organiza este juego romántico de las formas. El mismo iniciador del informalismo, Kandinsky, sucumbió al geometrismo y su obra lírica y eruptiva de la primera época comienza a dar paso a un mundo estructurado menos caprichosamente. Sin embargo, poco a poco la rigidez inicial se va aflojando como en Stuart Davis o George L. K. Morris y ya en la obra de Serge Poliakoff, por ejem- 
plo, los campos de color movidos en si, no están delimitados por líneas precisas sino encajan uno en otro en armónico ritmo sensual.

Hijo directo aunque desheredado de Dada es el Surrealismo que brota como movimiento literario en 1924; sin embargo, es hasta unos años más tarde cuando comienza a dar muestras de vitalidad en la pintura. Dentro de ésta disciplina no cabe duda que ha sido este movimiento eminentemente literario el que ha producido cuadros más interesantes junto con la abstracción.

El mensaje surrealista se extendió por casi todos los pafses que produjeron, bajo esta influencia, un arte simbólico o fantástico basado en el subconsciente, el sueño y la sin-razón y nacido de la imaginación supuestamente liberada de toda traba. Dos modalidades muy definidas aparecen en la pintura surrealista: la rama llamada del Surrealismo Verista que podriamos describirla usando la definición que Dalí ha dado a su obra: fotografías de sueños pintados a mano y que comprende al propio Dali, a Max Ernst, Pierre Tanguy, Paul Delvaux, René Magritte, Pierre Roy, Leonora Carrington, Remedios Varo, Juan O'Gorman y la obra de Wolgang Paalen de cierta época. La segunda, conocida como Surrealismo-Absoluto, tiene entre sus máximos representantes a André Masson y a Joan Miro, deja en total libertad correr la mano y la sensibilidad del artista que cubre la tela de ritmos, manchas de color o signos ininteligibles, produciendo una obra muy ligada a la abstracción.

La pintura de la irrealidad se ha apoderado de tal modo del espiritu del espectador que aún en aquellos pocos artistas apegados a un estricto realismo y cuya intención no es fantástica -Edward Hopper, Andrew y James Whyeth, Charles White, etcétera- el exceso de naturalismo y la perfección del oficio detallado producen un ambiente de paradójica ilusión fantástica.

El realismo auténtico existe en pocos exponentes y en los grandes pintores pone el énfasis en la anti-belleza y a veces en ciertas distorsiones como en el caso de Francis Bacon cuyo impacto expresivo estriba, entre otras cosas, en una rebuscada y muy estudiada cualidad de pintura lamida. Juan Genovés ha transformado con su realismo estricto los valores pictóricos en fotográficos logrando así un nuevo patetismo que transforma la pintura en algo distinto dentro de la tradición.

Una vez abierta la posibilidad de la libre expresión y divulgada la actitud y teorfa de Kandinsky y los primeros maestros de la abstracción, los artistas, basados en su diversos temperamentos y actitudes crearon una ilimitada variedad de conceptos plásticos dificil de catalogar. Sin 
DOI: http://dx.doi.org/10.22201/iie.18703062e.1968.37.859

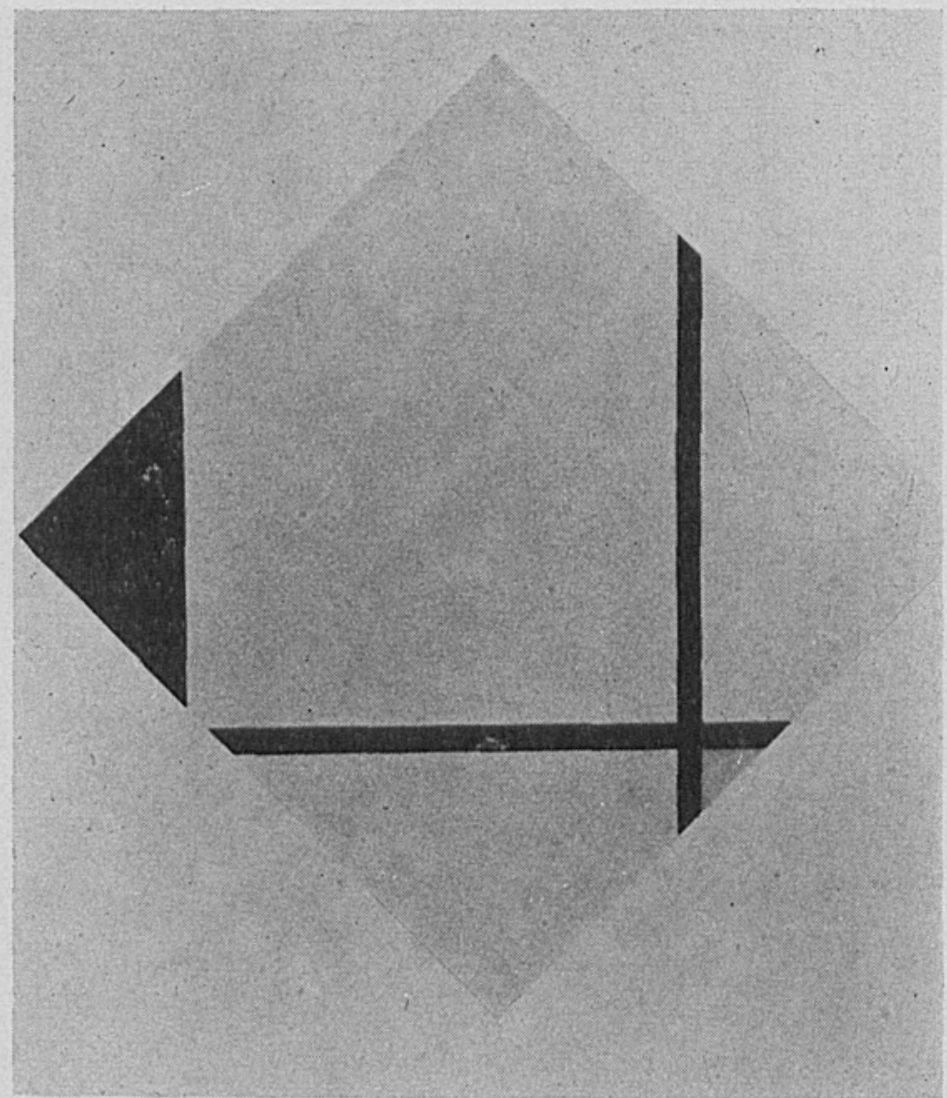

1. Piet Mondrian. Composición Núm. 1. 1925

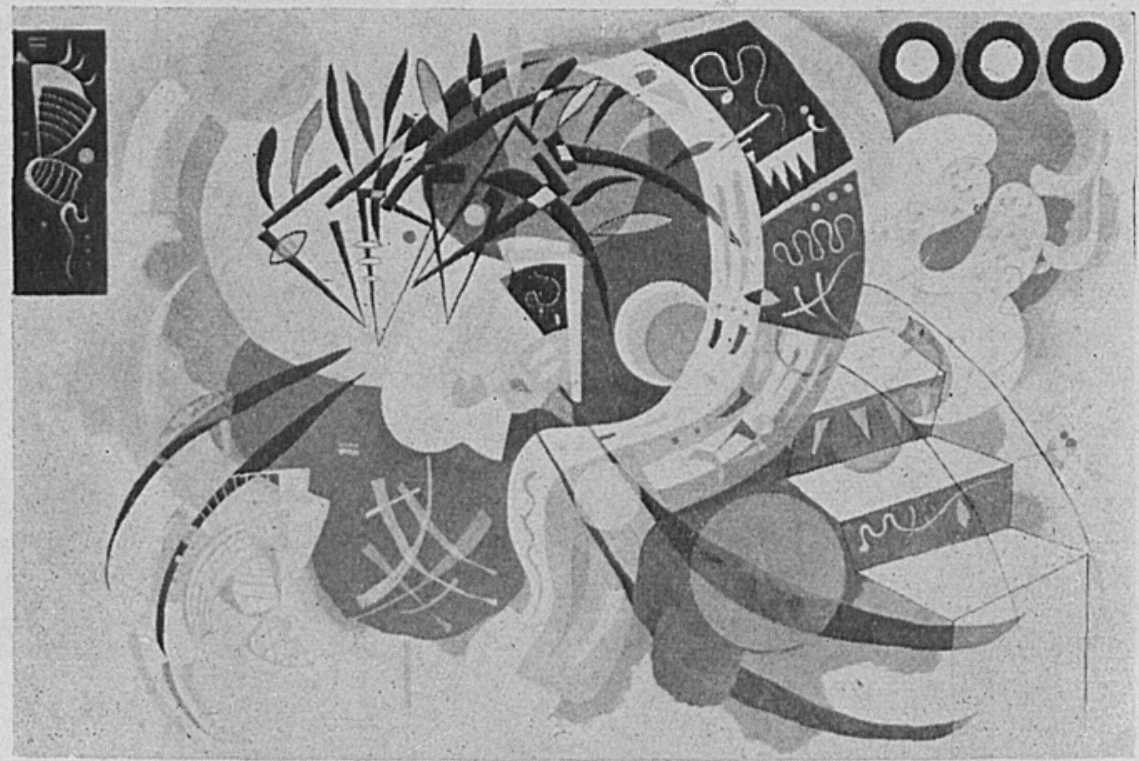

2. Vasily Kandinsky. Curva dominante Nüm. 631. 1936 
DOI: http://dx.doi.org/10.22201/iie.18703062e.1968.37.859

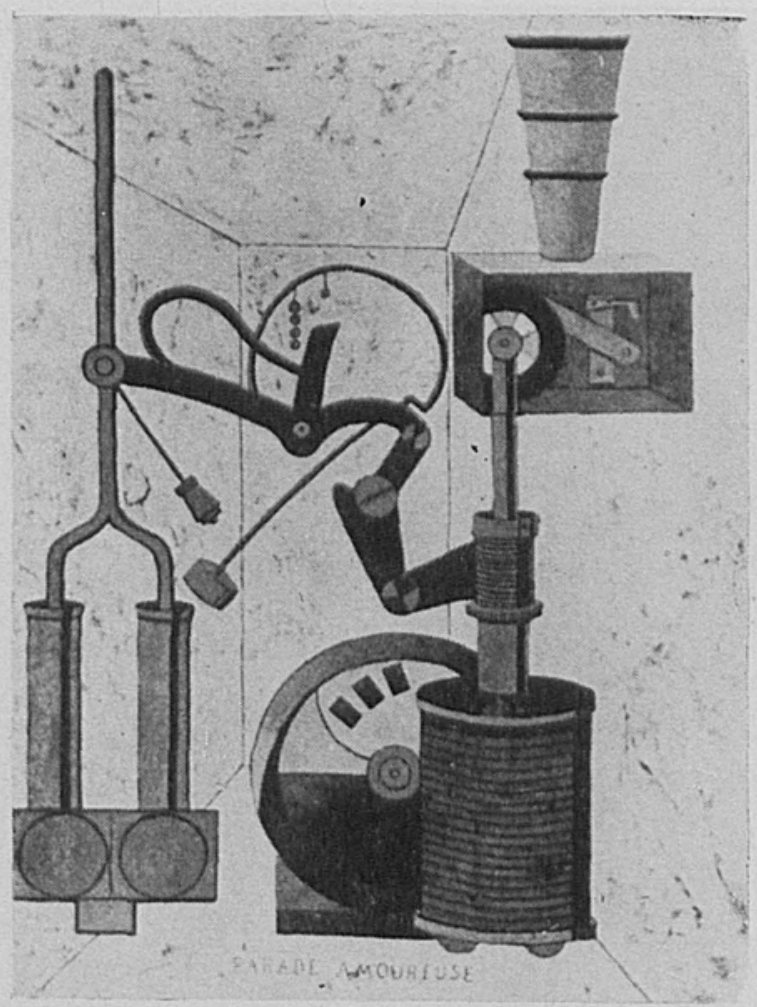

3. Francis Picabia. Parade amoureuse. 1917

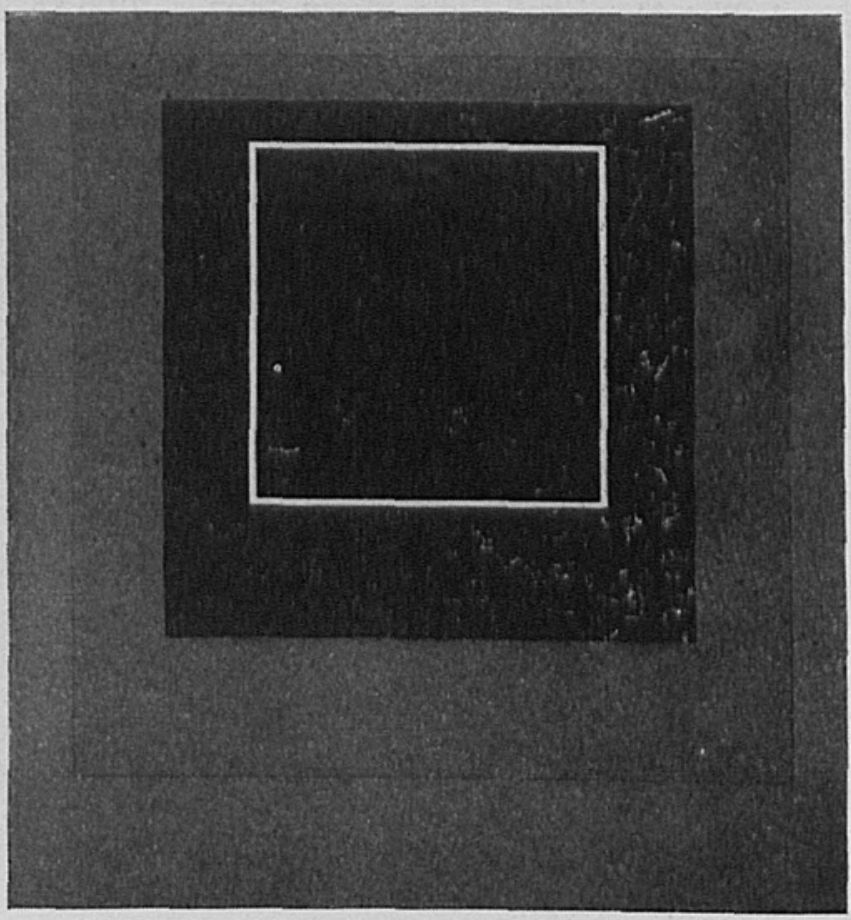

4. Josef Albers. Homenaje al cuadrado. 1967 


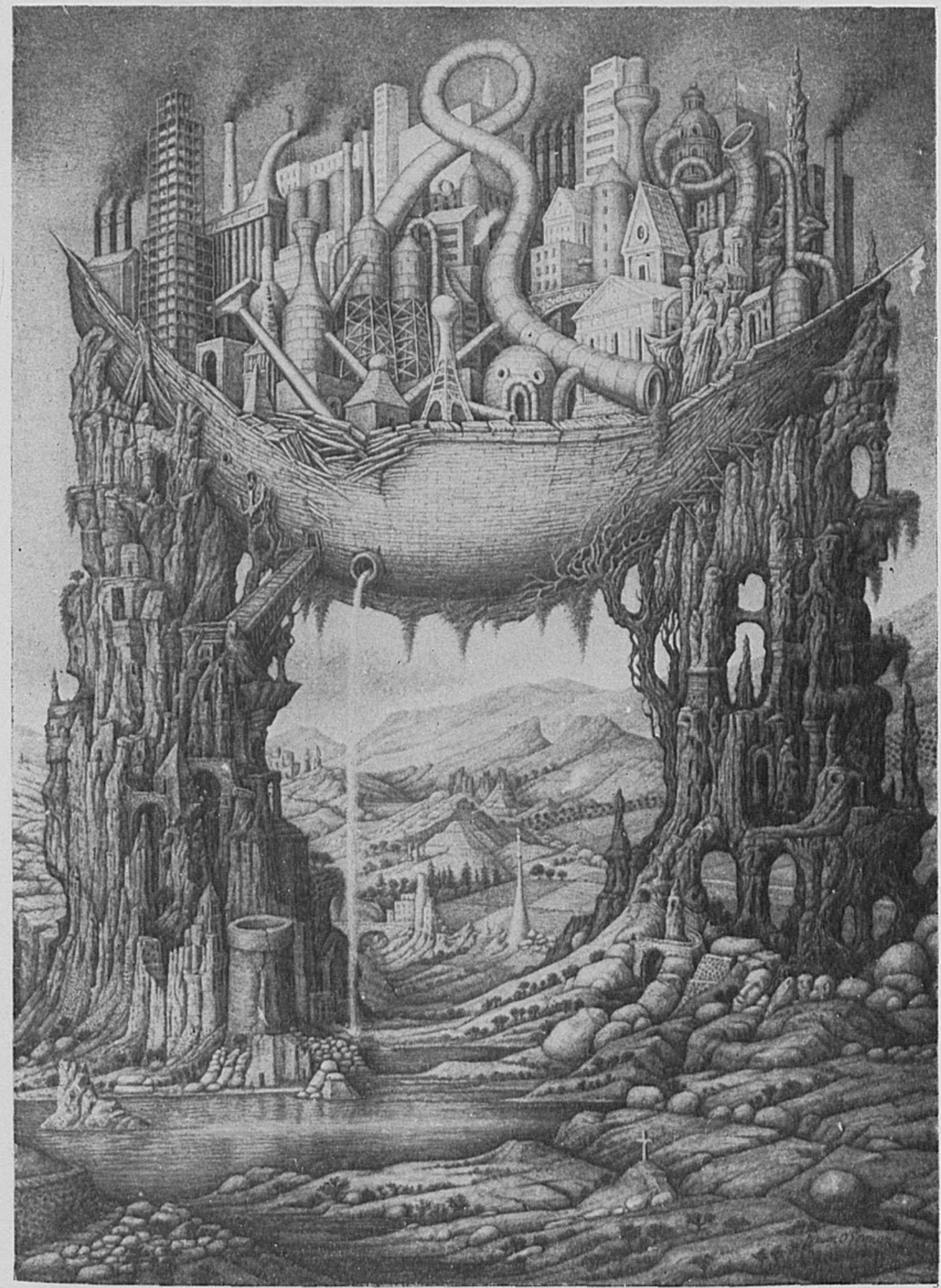

5. Juan O'Gorman. Lo que trajo el arca. Temple. 1967 


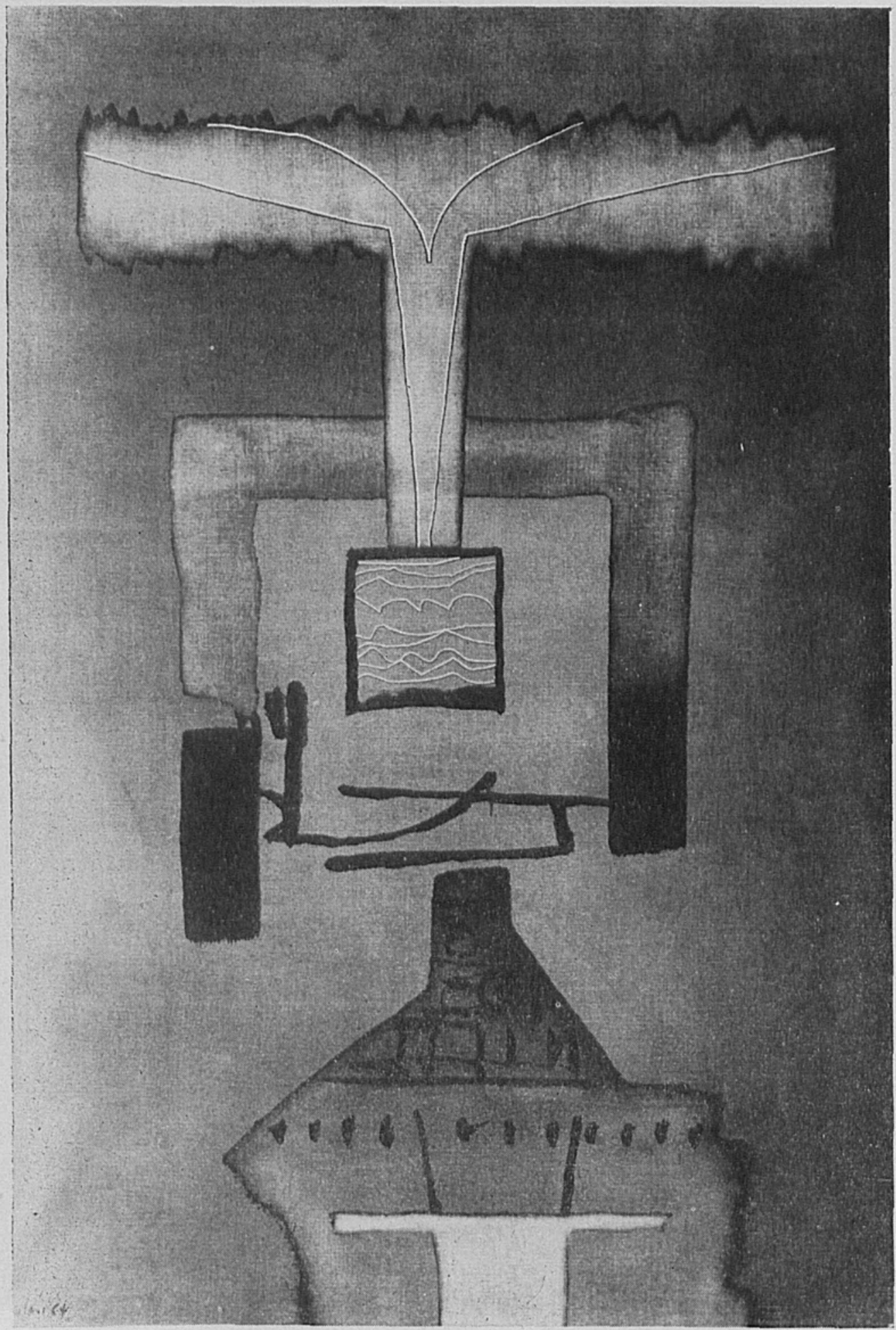

6. Heinz Trökes. La respuesta del oráculo. 1964 


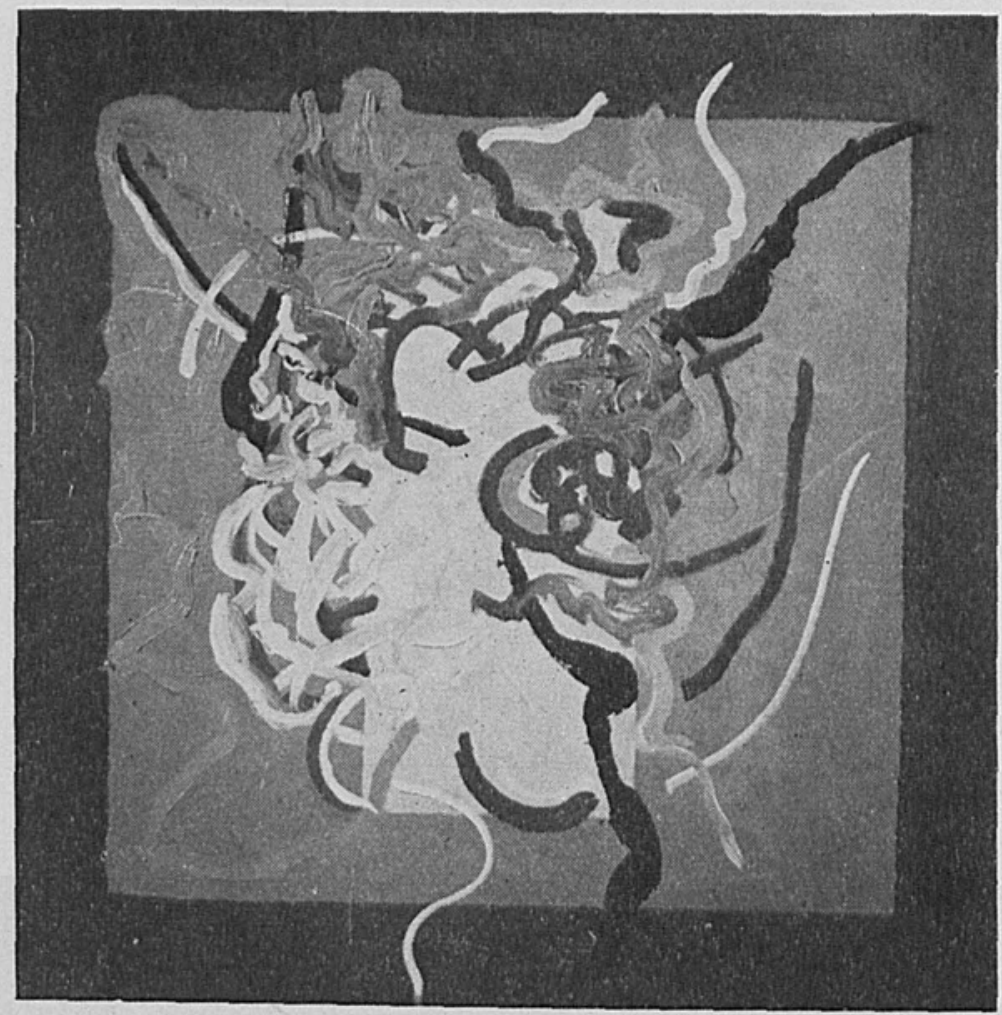

7. John Ferren. La rosa irlandesa. 1962

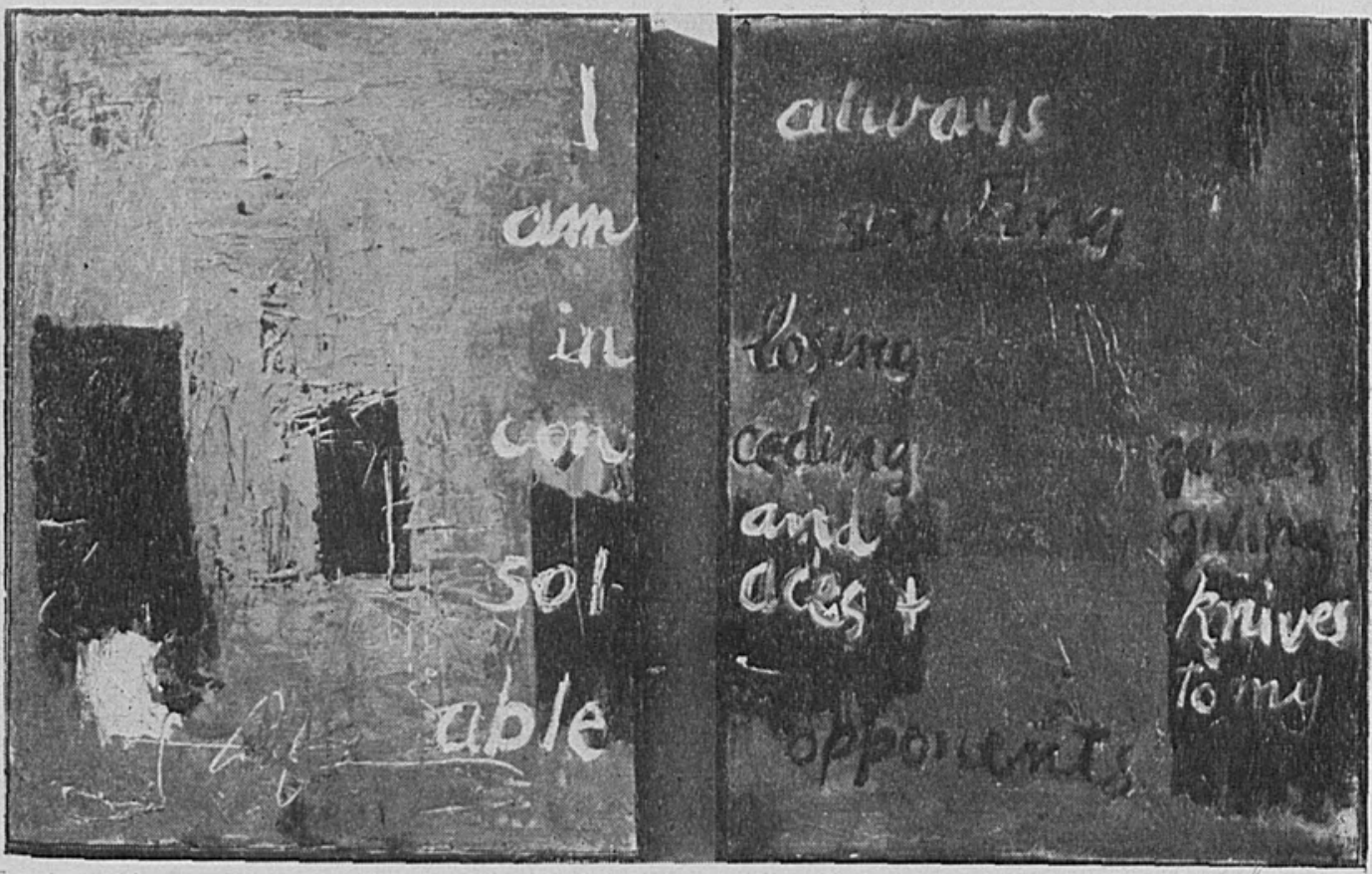

8. Al Kotin. Dúo. Poema pintura. 1960 


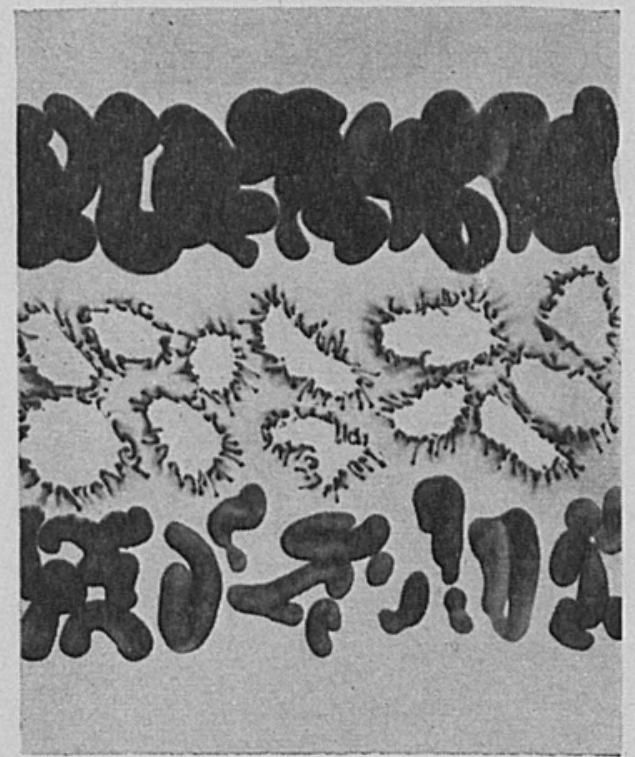

9. Alcopley. Acuarela sobre seda. 1956

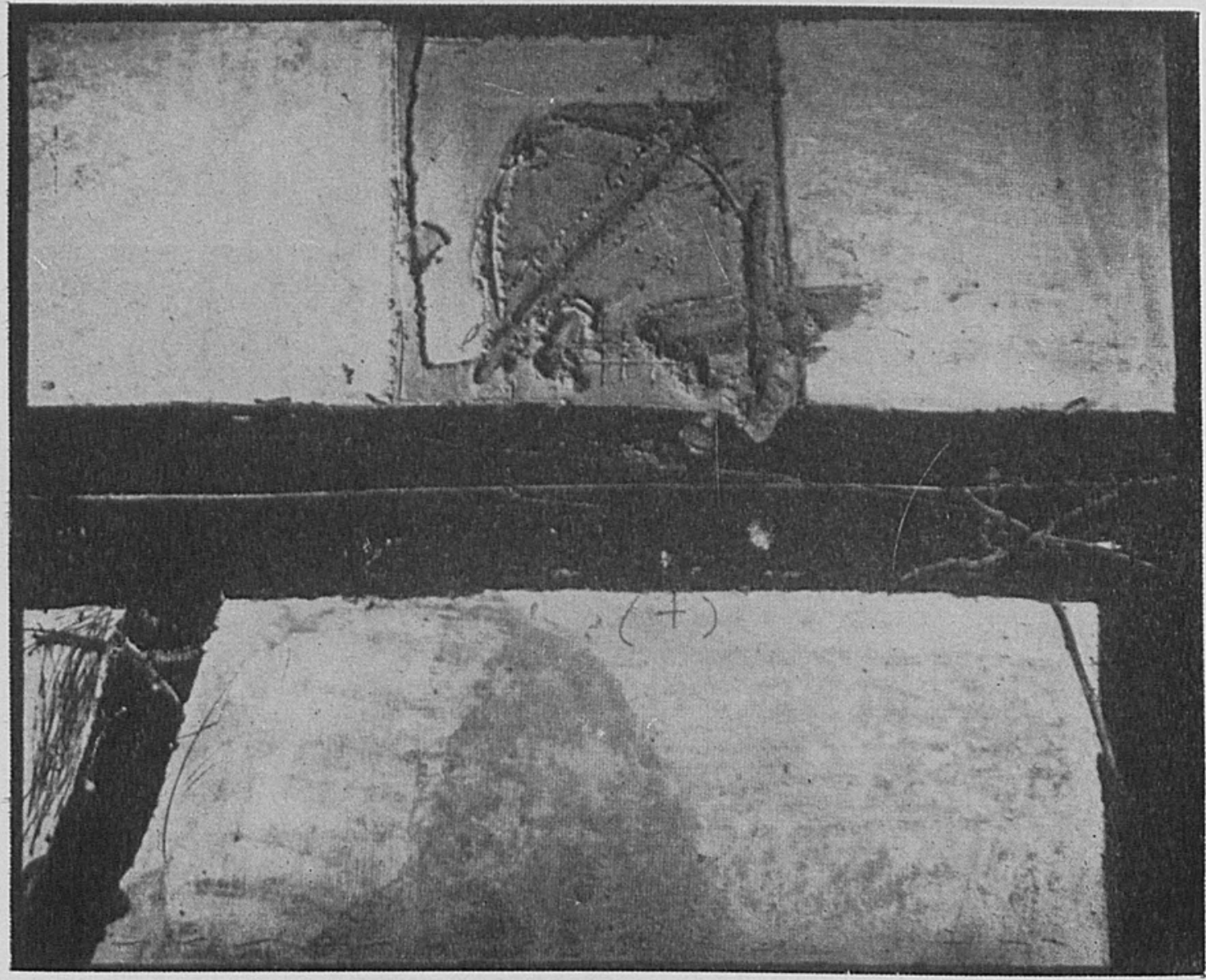

10. Antoni Tapies. Pintura. 1968 


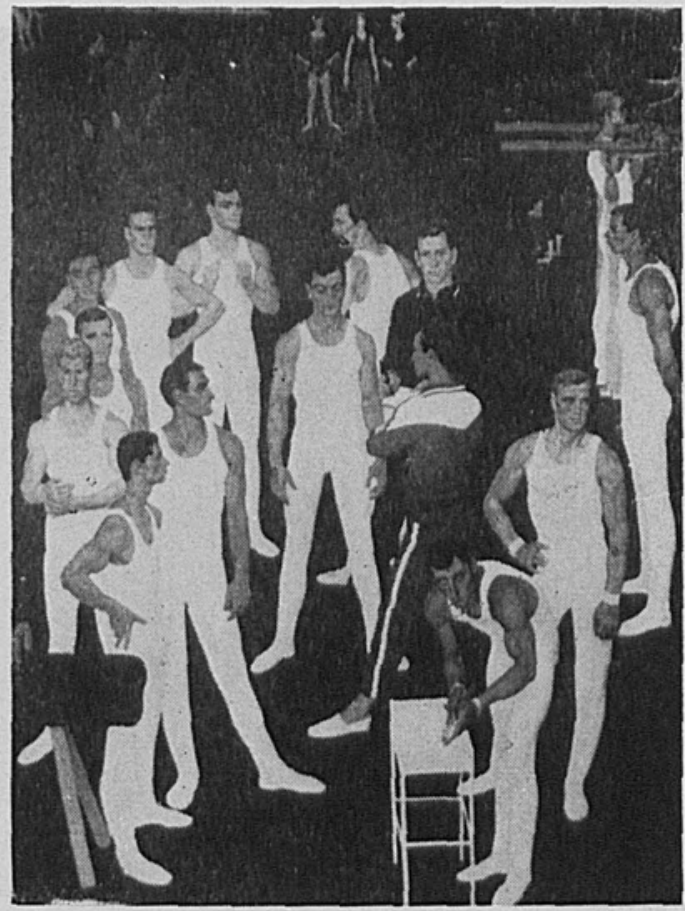

11. D. Thilinsky. El grupo de gimnastas

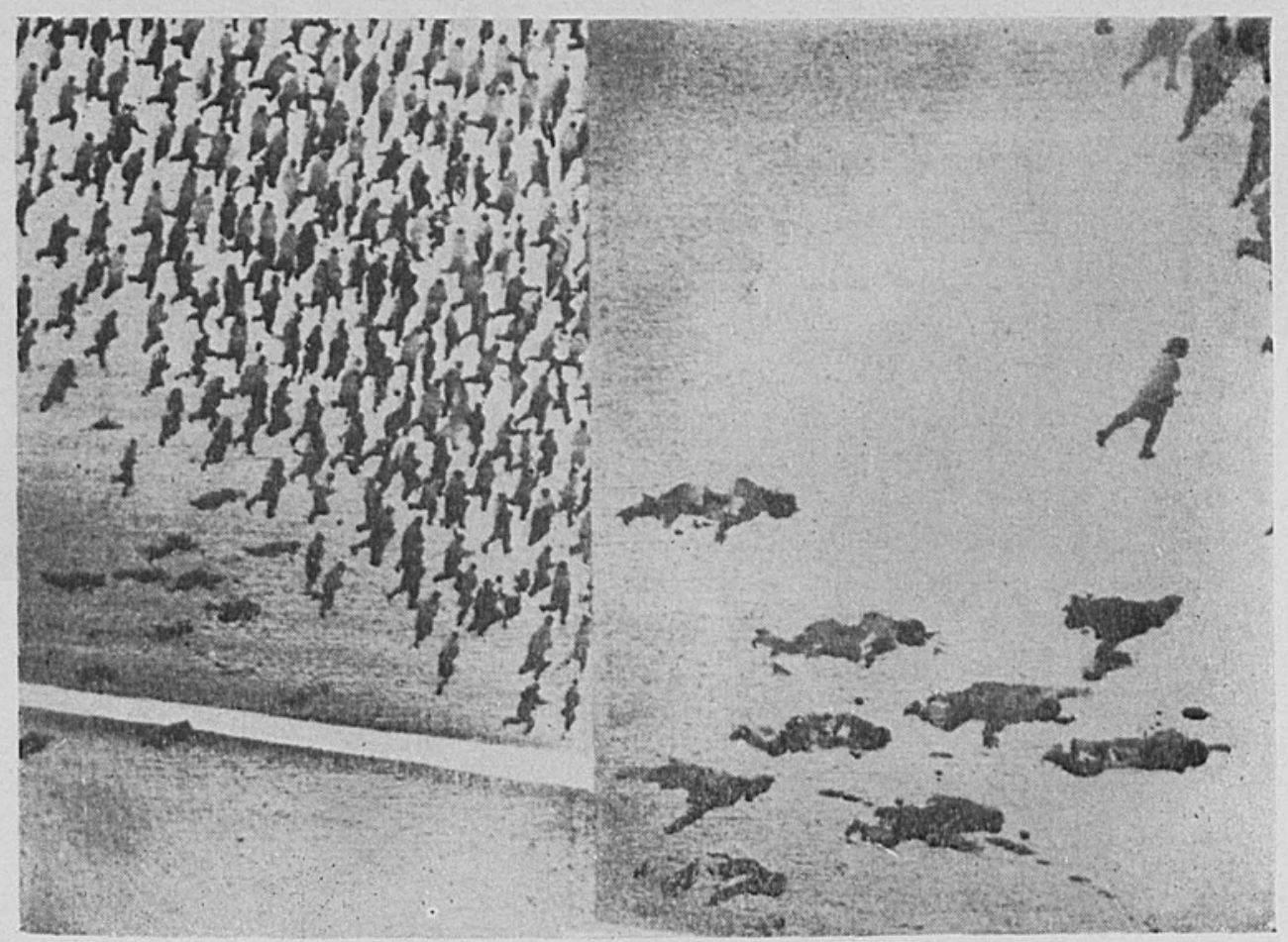

12. Juan Genovés. Un poco más cerca. 1965 
DOI: http://dx.doi.org/10.22201/iie.18703062e.1968.37.859

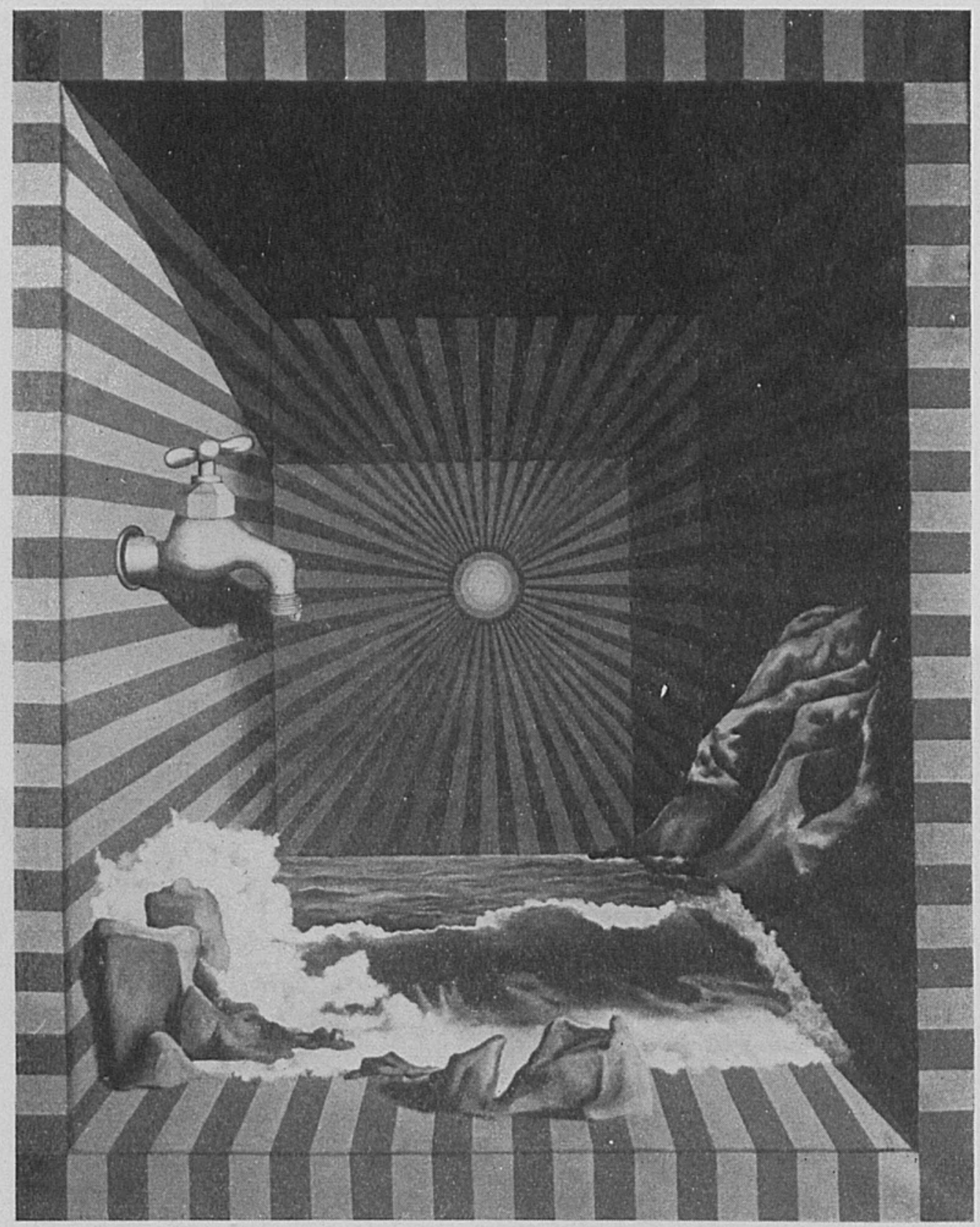

13. Javier Esqueda. Atardecer en Acapulco 
DOI: http://dx.doi.org/10.22201/iie.18703062e.1968.37.859

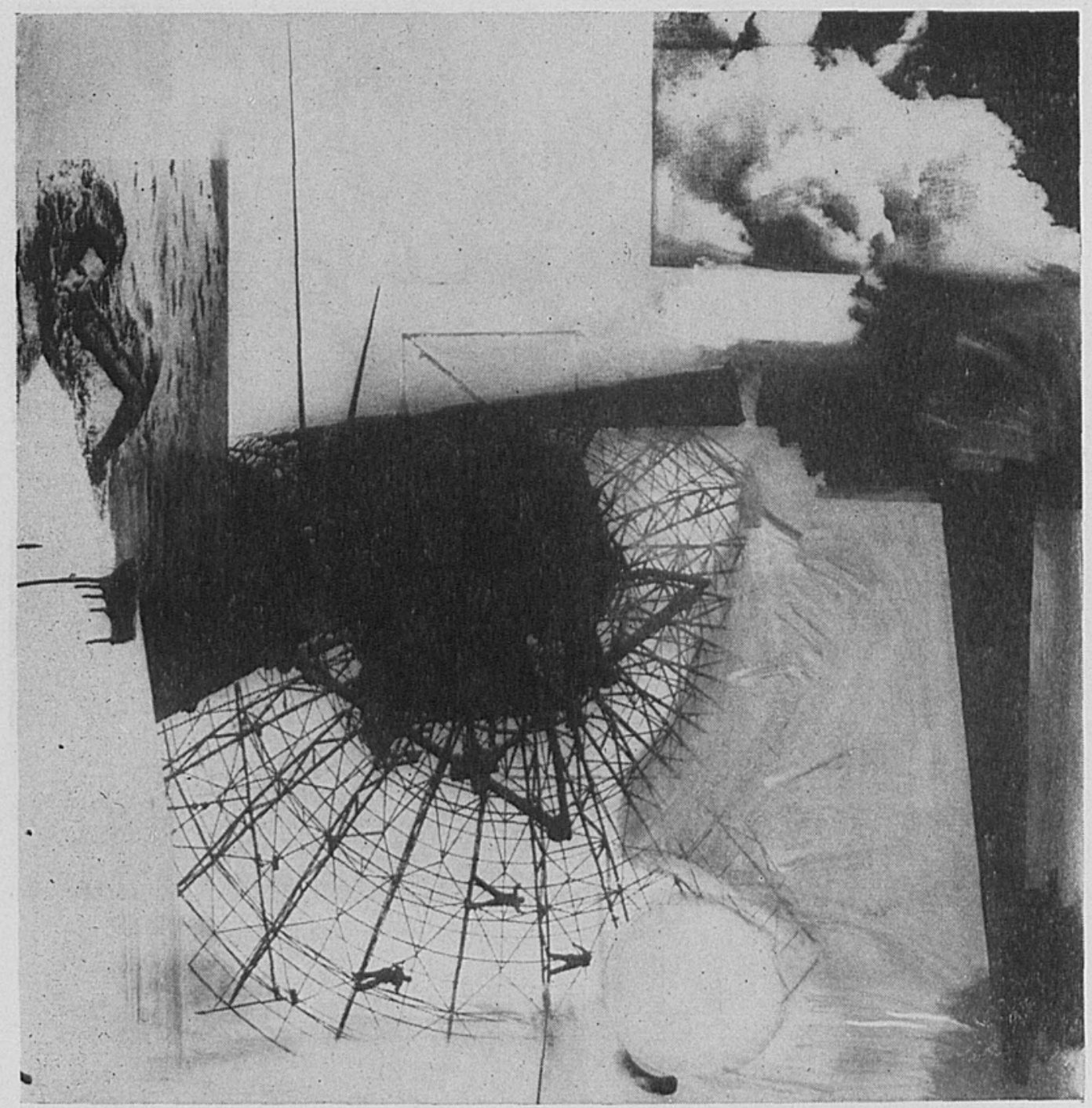

14. Robert Rauschenberg. Sol de perro. Óleo sobre tela. 1962 
DOI: http://dx.doi.org/10.22201/iie.18703062e.1968.37.859

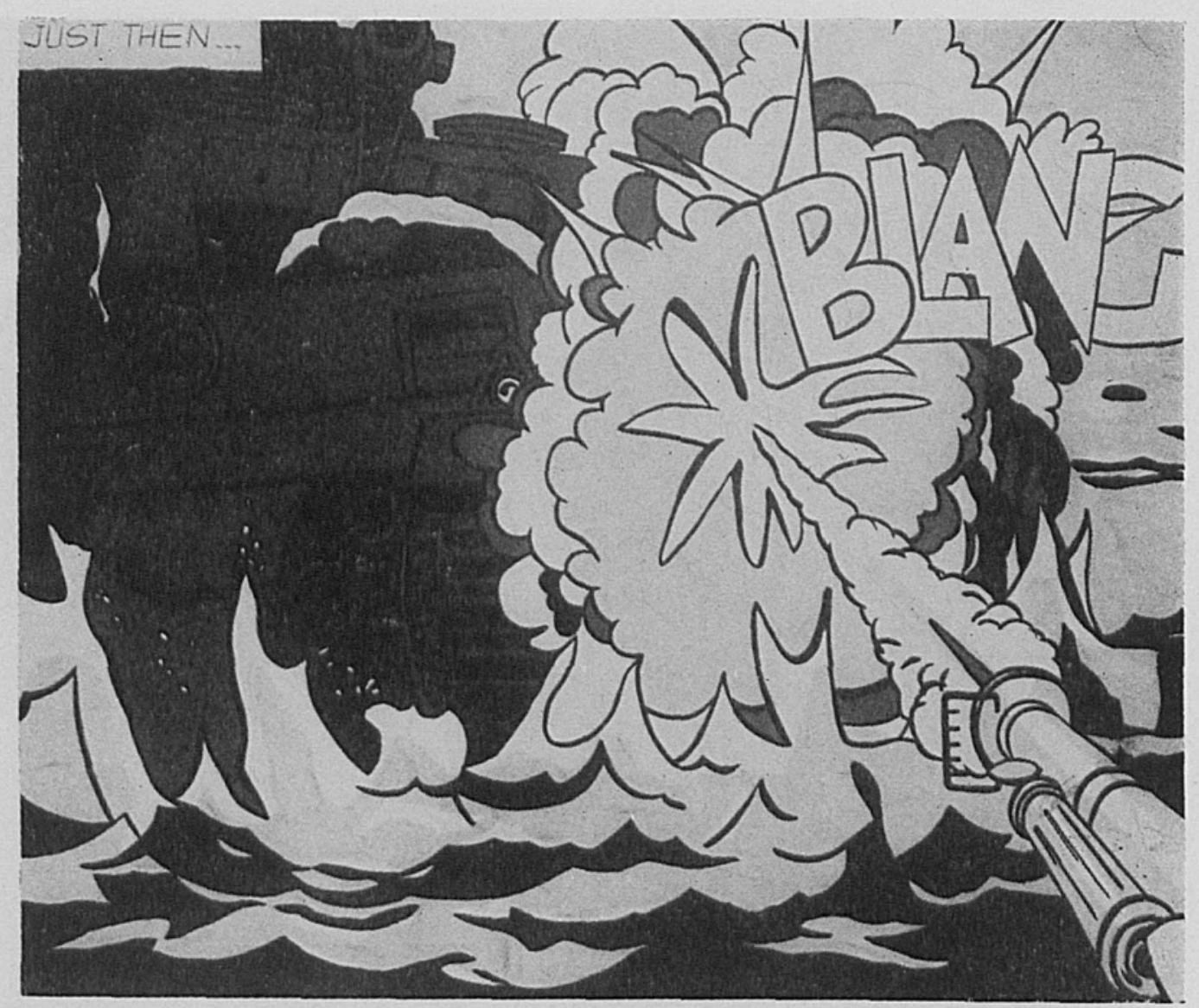

15. Roy Lichtenstein. Blang. Óleo sobre tela. 1962 
DOI: http://dx.doi.org/10.22201/iie.18703062e.1968.37.859

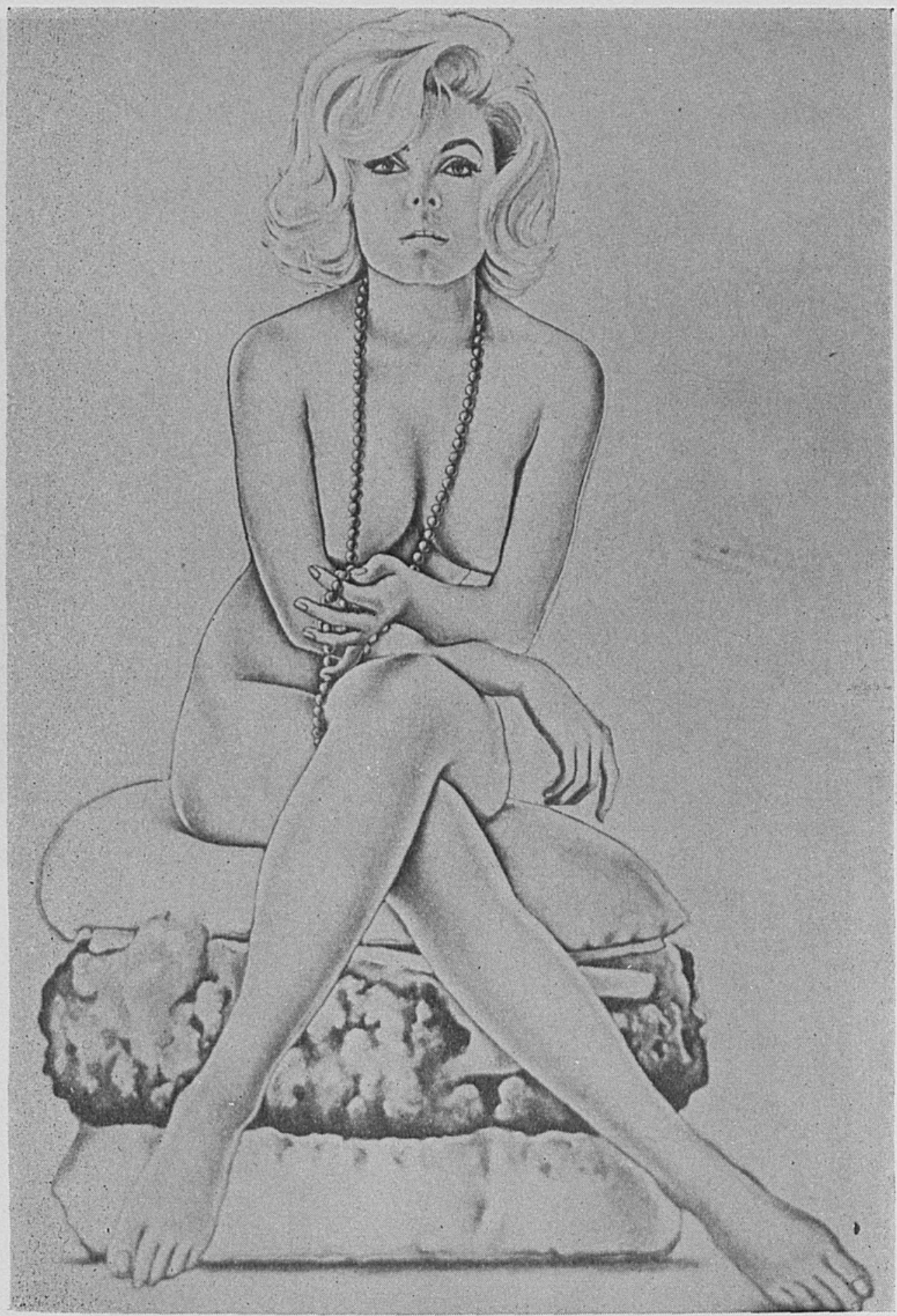

16. Mel Ramos. La muchacha de la hamburguesa. 1965 
DOI: http://dx.doi.org/10.22201/iie.18703062e.1968.37.859

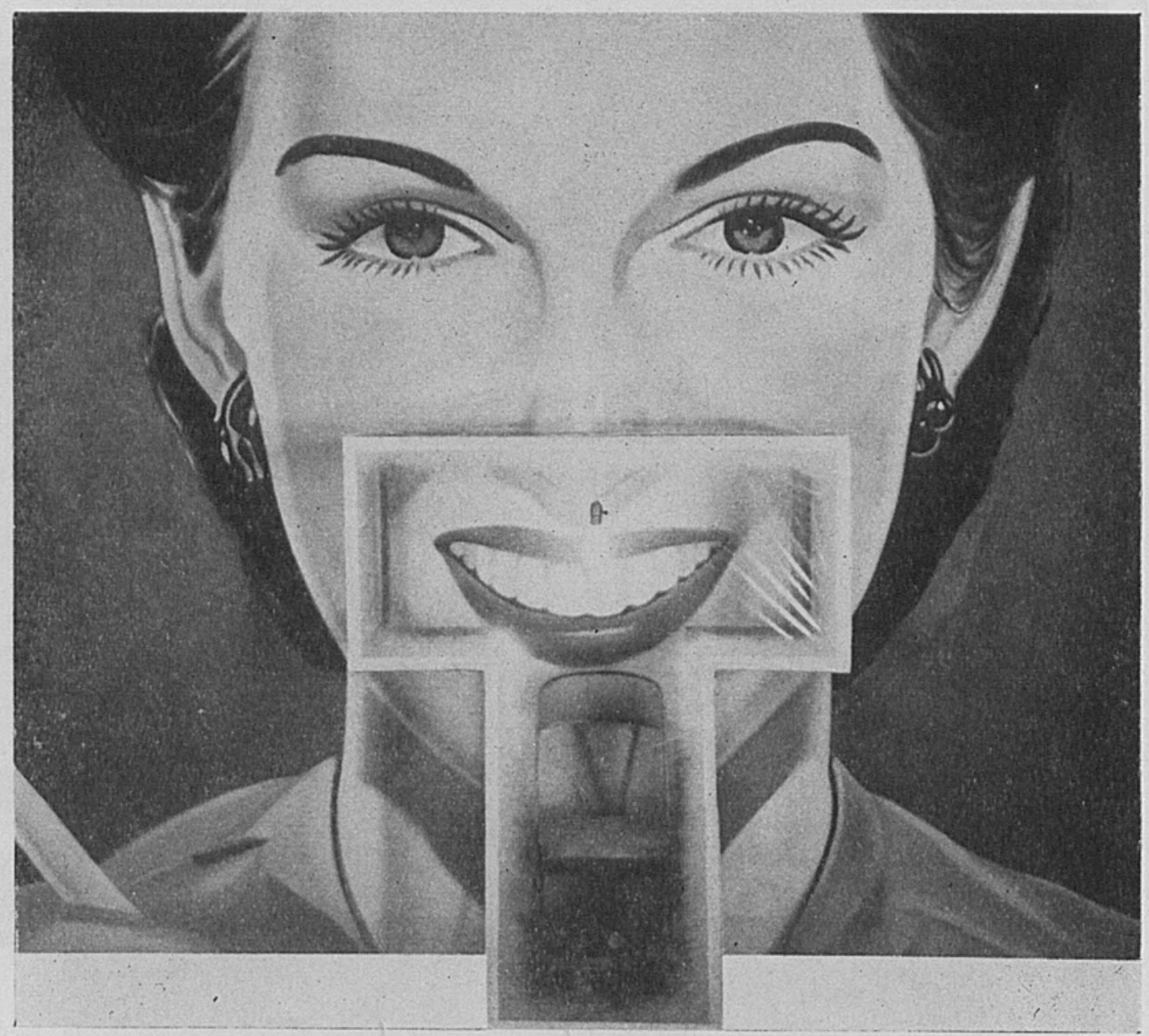

17. James Rosenquist. Candidata. 1963 


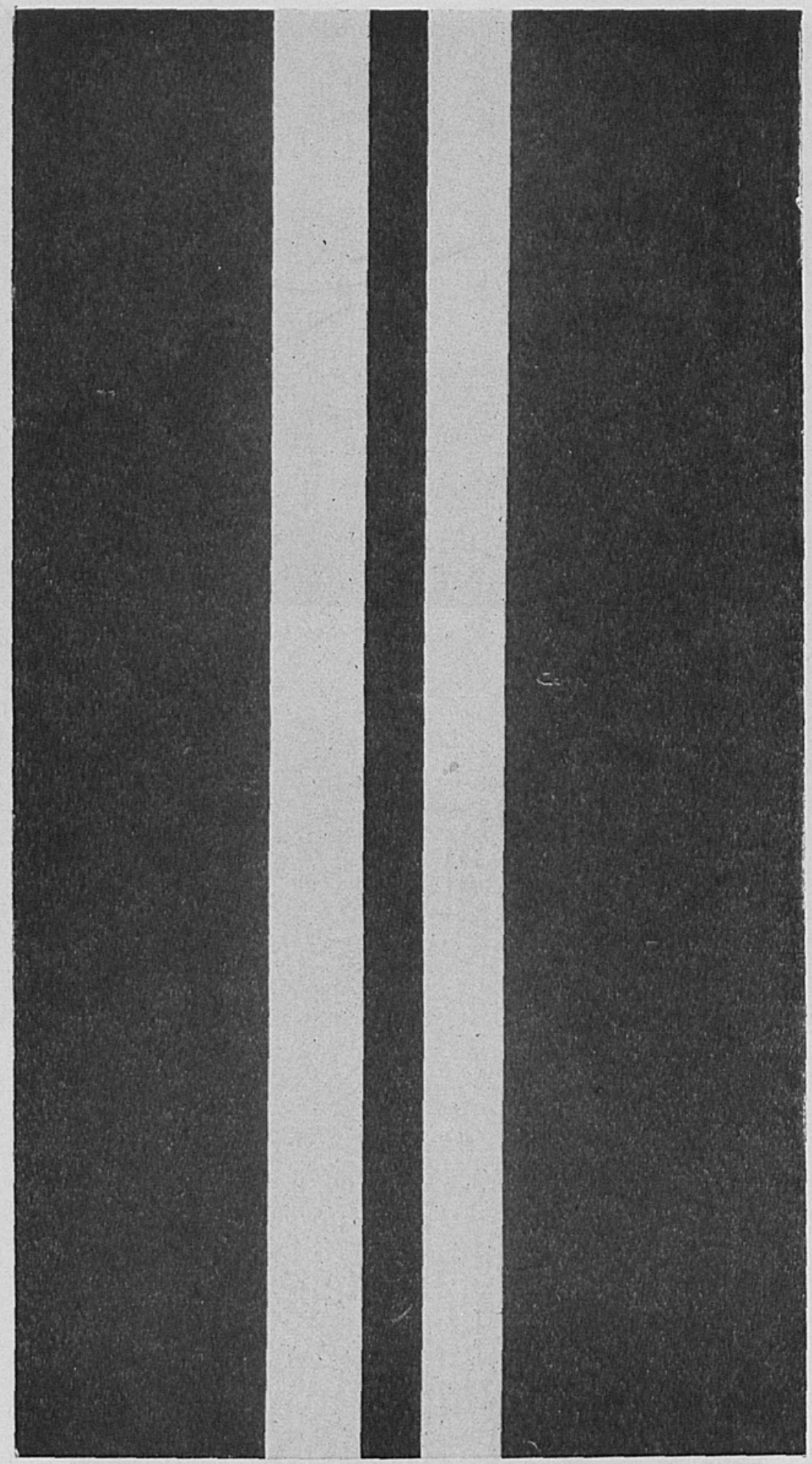

18. Nassos Daphnis. Pintura 
DOI: http://dx.doi.org/10.22201/iie.18703062e.1968.37.859

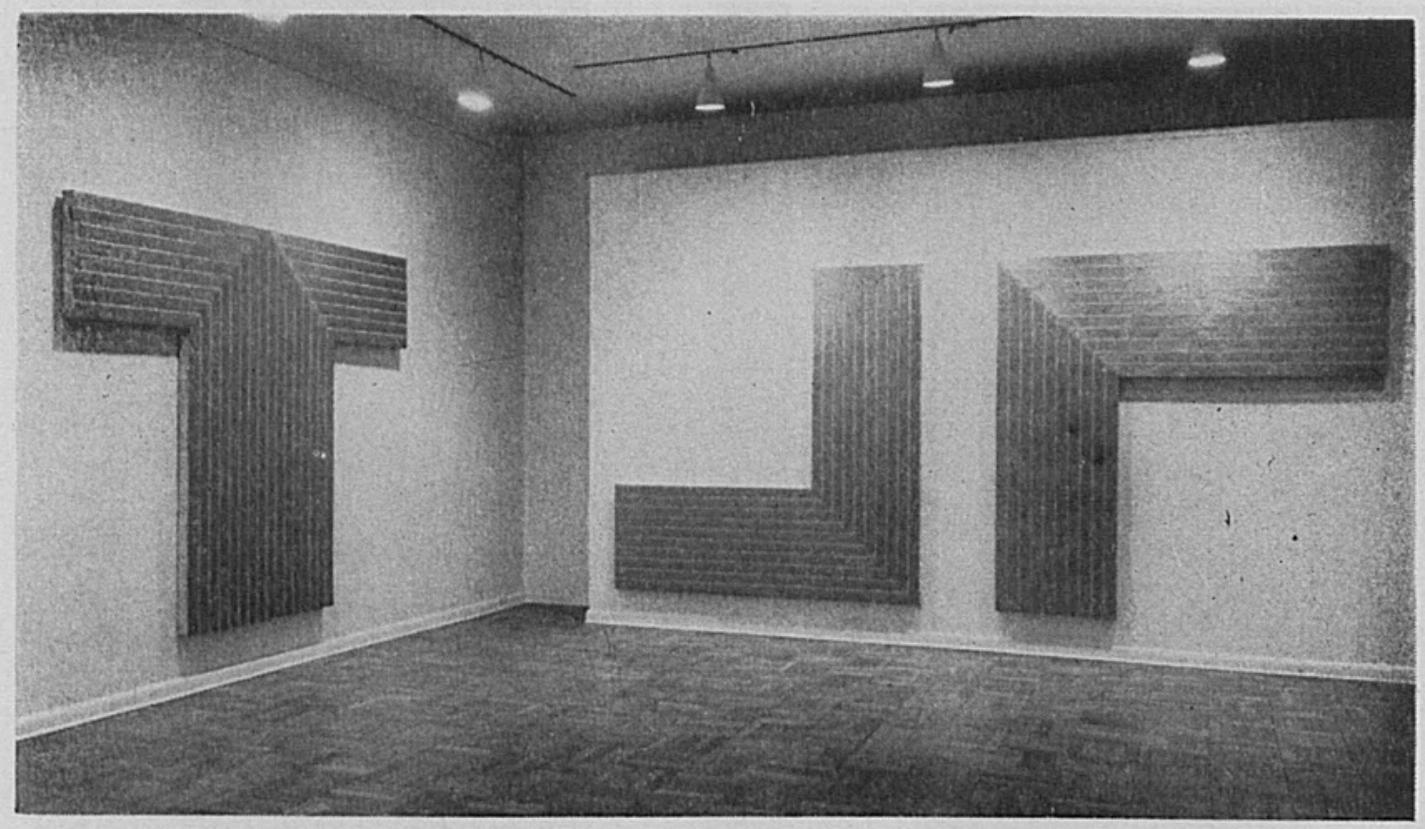

19. Frank Stella. "Telluride" Creede $I$ o II

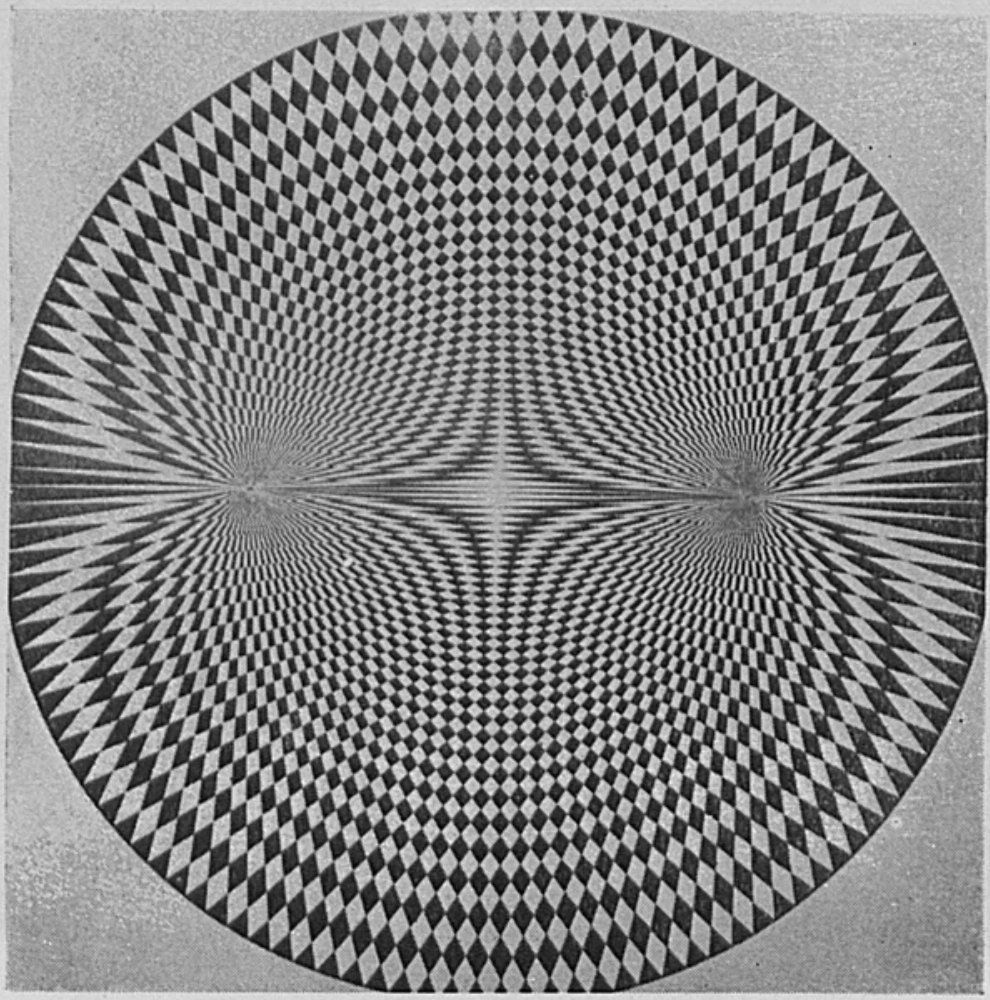

20. L. Mario Lareaga. Figura óptica 


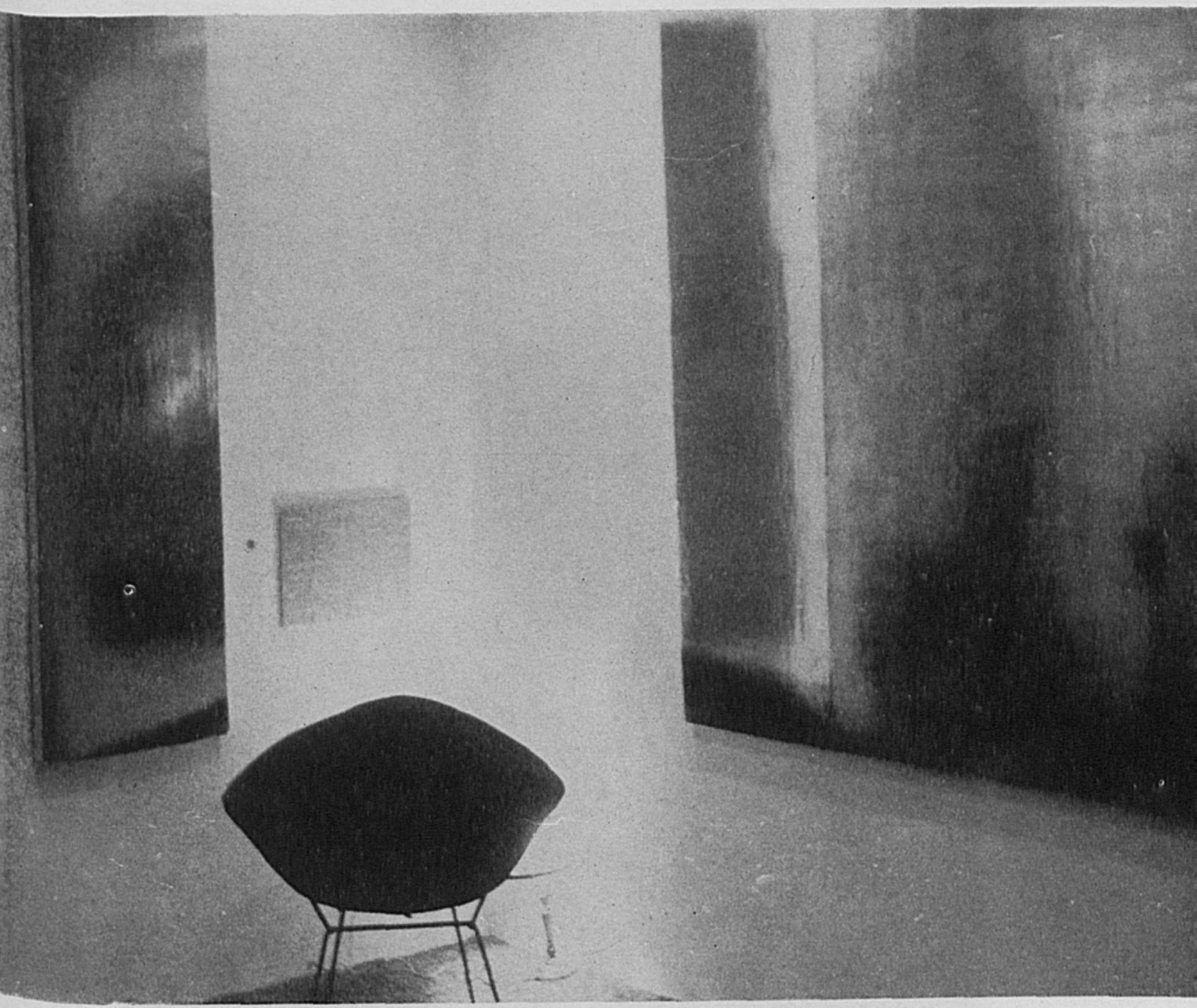

21. Mathias Goeritz. Mensajes Metacromáticos. 1959-60. Exposición: Galeria de Antonio Souza, México, D. F. (I960) 
DOI: http://dx.doi.org/10.22201/iie.18703062e.1968.37.859

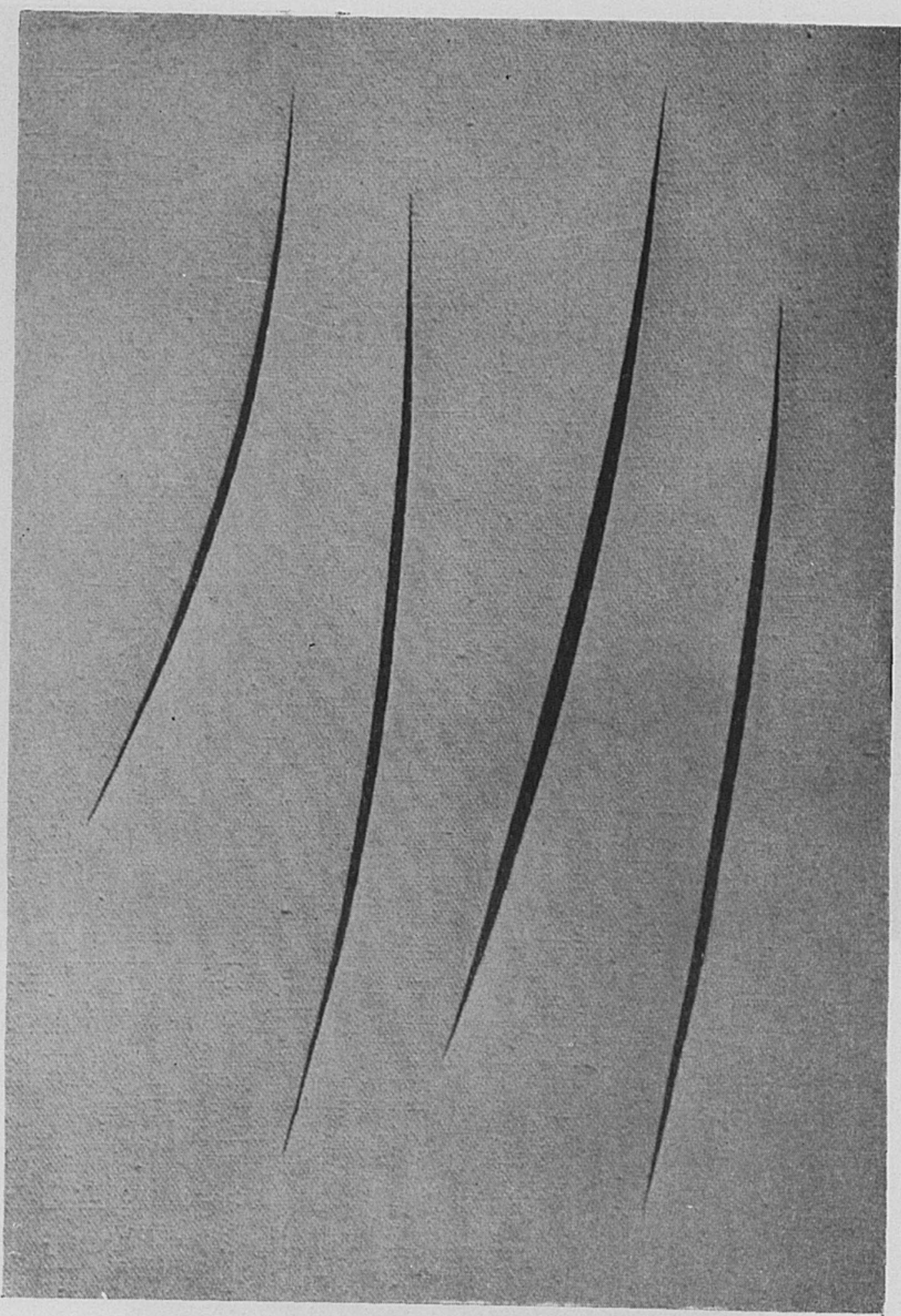

22. Lucio Fontana. Concepto espacial - Espera. 1964 
embargo, existen ciertas características que unen a determinados artistas y con éstas se pueden formar varios grupos. El fluir del color hasta formar constelaciones de manchas amorfas ha sido una de las corrientes más concurridas. El color extendido sobre la tela, yuxtapuesto, corroldo, adulterado o goteado no está contenido dentro de formas limitadas, sino deambula con holgura como producto de la sensibilidad del artista que a veces lo expande arbitrariamente -Wols, Karl-Otto Götz, Camille Bryen, Henri Michaux, Jean Bazaine, Julius Bissier, Mark Tobey, etcétera.

Otras veces los pintores organizan un poco más el cuadro (sin llegar al geometrismo) pero reprimen y cuidan sus pinceladas desbocadas en favor de una parcial estructuración -Nicolás de Staël, Alfred Manessier, Roger Bissier, Gustave Singier, Pierre Soulages, Andrés Lanskoy, Fritz Winter, Willi Baumeister, Ernst Wilhelm Nay, Maria Elena Vieyra da Silva, etcétera.

Esta corriente abstraccionista lírica o expresionista muy pronto se enriquece con el goce de la materia plástica más que con el color y así, la textura se impone como primera condición y surge otra modalidad. Jean Fautrier sostiene, junto con otros, la clave en esta dirección que tiene representantes sobresalientes, especialmente en Europa, cuya pintura, más preocupada por el refinamiento técnico da excelentes muestras de una nueva estética o Arte Otro. A ella pertenece la Joven pintura española que empieza con la Escuela de Altamira y culmina a través de las obras de Antoni-Tapies, Luis Feito, Manolo Millares, Lucio Muñoz y otros y conduce al aprovechamiento de los materiales, y a la construcción de una realidad más táctil que visual. Detrás de la cortina de hierro, en Polonia, Jean Lebenstein es el más ilustre representante de esta modalidad abstracta. El italiano Alberto Burri ha aprovechado el uso de diversas técnicas y materiales, generalmente despreciables para enriquecer la superficie creando rugosidades, resquebrajaduras, ampollas, grietas o empastes que forman, por sí mismos, un nuevo universo matérico. Pero el empleo de sacos, telas, cartones, láminas, etcétera, alejan a Burri del cuadro propiamente pintado y lo incluyen con mayor validez dentro de la nueva categoria de Collage que, lentamente, ha ganado en éxito e interés a la pintura propiamente dicha.

El caso de Jean Dubuffet, creador del Arte-Bruto, es en cierta manera similar al de Burri en la transformación de la materia, aunque gran parte de su obra sí puede incluirse dentro del arte puramente pictórico. Dubuffet ha consumido y apreciado el "arte de los niños", el grafismo 
callejero, las deformaciones grotescas de la figura, los mundos micro y macrocósmicos, hasta invertir los valores y crear la estética de lo repulsivo, brutal y diabólicamente refinado.

Dentro de la abstracción, la escuela que surgió con mayor coherencia y vitalidad, fue la del Expresionismo-Abstracto norteamericano o PinturaAcción. Movimiento eminentemente romántico, surge como destilado del surrealismo, la abstracción y las inquietudes filosóficas que habían despertado doctrinas orientales recientemente importadas: Zen, Bahái-. Sin tratarse de una actitud antiartística o antipictórica, el artista norteamericano -Jackson Pollock, Franz Kline, William De Kooning, Theodoros Stamos, Robert Motherwell, Clyfford Still, Al Kotin, Philip Guston, Adolph Gottlieb, etcétera-, marca el énfasis en la acción y no en la pintura. De acto en acto va llenando su existencia y construyendo una obra por la aventura de gesticular. Al pintor de la acción ya no le interesa en primer plano el producto de su actuación, lo que le importa primordialmente es la descarga psíquica de su personalidad. La afirmación de su yo en el trance de embarrar o gesticular ante un lienzo. Las preocupaciones teóricas, estéticas, refinadas, conscientes, pasan a un segundo término y el automatismo, la intuición, la espontaneidad, la libertad total, el mundo interior constituyen el drama único y valedero. Quien asiste al milagro de esta creación no está capacitado para juzgarla; puede rechazarla o aceptarla, pero no tiene términos medios, ya que está ante la presencia de un ser humano al desnudo que no aspira sino a que se reconozca su ser, su existencia.

En Europa la pintura del gesto tiene también valiosos representantes. Baste recordar como a los más consecuentes al alemán-parisino Hans Hartung cuyas caligrafías en variaciones seriales reducen a signos sus actitudes y a Georges Mathieu, gesticulador ante el lienzo y creador de esquemas ideológicos aumentados, pero sin contenido.

Una especie de caligrafía personal ha nacido de la inspiración de los caracteres orientales - Alcopley, Shiryu Morita-, o de la búsqueda de un nuevo emblema ideográfico-Giusseppe Capogrossi.

No cabe duda que el triunfo de los pintores y entre los que se encuentran los más festejados universalmente, está dentro de la semifiguración o transformación de la realidad Georges Braque, Pablo Picasso, Henri Matisse, Fernand Léger, Marc Chagall, Paul Klee, Graham Sutherland, Rufino Tamayo, José Luis Cuevas, Matta, Wilfredo Lam, para nombrar solamente unos cuantos y miles de otros artistas que creen en y continúan sosteniendo vivos los ideales pictóricos. Aunque 
muchos de ellos -Picasso, Matisse, Léger, Miró- ampliaron la creación a otros campos como la ilustración, la escultura, la cerámica, el mural, puede decirse que son los que han sostenido, a pesar de los cambios, las rupturas, las novedades plásticas de la nueva estética, un apego a la tradición de la pintura como una de la Bellas Artes, sin ninguna inquietud o mensaje social o político y se han sostenido dentro de la esfera del arte puro o arte por el arte. Con la gran excepción del Guernica, en el cual la obra de Picasso se levanta a su más excelsa cumbre, este grupo de artistas merece, adecuadamente, el nombre de "pintores".

La pintura de caballete de los artistas de la revolución mexicana dentro de un expresionismo más o menos realista o fantástico, también encaja en la pintura tradicional por carecer, en gran medida, de los ideales revolucionarios, nacionalistas o humanistas que hizo único y distinto a este movimiento muralista al que pertenecieron.

No debe pasarse por alto en la historia de la pintura al grupo Cobra (1948) - Karel Appel, Asger Jorn, Corneille y Pierre Alechinsky-, que intenta mezclar la pincelada abstracta brutal e impetuosa con un nuevo figurativismo. Estos pintores afirman: Una pintura no es una construcción de colores y lineas, sino un animal, una noche, un hombre o todo esto junto; pero con tal violencia-destructiva que sus ligas con el expresionismo abstracto son obvias.

Tampoco es posible, al hablar del "realismo", olvidar el naturalismo fotográfico, el extremado apego al buen oficio que han producido muchos pueblos bajo el gobierno dictatorial. Al hablar de pintura de la Alemania Nacional Socialista o de la Rusia Stalinista podemos referirnos a la supervivencia o retorno de la "buena pintura", pero es muy dudoso que podamos, en estos casos, hablar de Arte.

La rama que contenía el infantilismo de Henri Rousseau tampoco ha desaparecido sino, por el contrario, sigue viva en innumerables artistas naives. Es, hasta alrededor de 1960 , cuando se presenta otra revolución en donde la pintura comienza a pasar a un plano secundario. Las nuevas formas y nuevos medios y el arte del Ensamblado dominan la vanguardia artística por estos años. La revolución Neo-Dada convierte los valores rotos, las hazañas incongruentes de los dadaístas en fuente viva de inspiración formal y la pintura, definitivamente por ahora, pierde sus fueros. En 1962 hay un resurgimiento del cuadro, pero con un muy distinto motor que el del "arte por el arte". Como reacción al arte abstracto hermético e individualista y al surrealismo decorativo, literario y fantástico, un nuevo espejo refleja al hombre y sus inquietudes, sur- 
giendo al unisono en Europa y Norteamérica con los nombres de NuevoRealismo y Pop-Art, respectivamente. Lo que estos artistas levantan como imagen del hombre y la sociedad y sus ambientes, son los carteles cursis y directos, los dibujos amplificados de historietas para niños, los anuncios de los objetos de las casas comerciales: Coca-Cola, hamburguesas, hot-dogs, jabones, llantas, etcétera; las atmósferas típicas de los alrededores circundantes son el acopio que, limpiamente presentado, usan estos artistas. Robert Rauschenberg, Jaspers Johns, James Rosenquist, Wayne Thiebaud, Tom Wesselmann, Roy Lichtenstein, Mel Ramos, Robert Indiana, Andy Warhol, Valerio Adams, Martial Raysse, Richard Hamilton, Konrad Lueg, Jack Stuck, Peter Stämpfli, etcétera.

En la obra de estos artistas no hay posibilidad de que exista otro mensaje que el más directo y vulgar, nuevamente el artista pugna por una comunicación efectiva con el público. La pintura carece de todo preciosismo, refinamiento y está reducida a una voluntaria, mediocre pintura de cartel que intenta volver, con nuevos brios, a establecer una natural e inmediata comunicación con el público.

El surrealismo, por su parte queda vivo en otro "neo", el neo-surrealismo con su fuerte esqueleto literario, pero ahora aprovechando los encuentros formales de la historia del arte hasta el Pop y el $O P$-Pedro Friedeberg, Benno Waldorf, Pamela Bianco, Javier Esqueda, etcétera.

Las últimas modalidades que aparecen: el $O p A r t$ y un nuevo brfo del hard edge o pintura de línea dura derivan de las corrientes geométricas abiertas por los constructivistas, por De Stijl (especialmente Mondrian) por las búsquedas dentro de la Escuela de la Bauhaus y por la obra de Joseph Albers y del húngaro Víctor Vasarely. Ambas direcciones surgen en oposición muy directa al Pop-Art, al neo-surrealismo y a la abstracción tachista o informal.

El $O p-A r t$ fue consagrado en febrero de 1965 por una gran exposición que, bajo el título The responsive eye tuvo lugar en el Museo de Arte Moderno de Nueva York. Las variaciones infinitas de juegos ópticos fueron recogidas en este lugar. Perpetuas vibraciones, ritmos, vértigo, ansiedad, "trompe l'oeil" abstracto, cromatismo centelleante y una enorme disciplina constructiva son las caracteristicas de este arte que triunfalmente recibió la acogida de la masa del público que por fin pudo sentir que tenía acceso al arte de su tiempo, fuera de las obvias vulgaridades del Pop-Art. Richard Anuszkiewicz, Larry Poons, Bridget Riley, Sue Fuller, Peter Sedgeley, Francis Ray Hewitt, Piero Dorazio, Reginald Neal, Karl Gerstner, Lynn Leland, se cuentan entre los principales maes- 
tros de este arte fascinador que abrió las compuertas a una nueva valoración de los cambios visuales por medio de la luz y el movimiento -Arte Cinético- que nada tienen que ver ya con lo que se llama pintura.

Paralela a la escultura de las Estructuras Primarias corre la corriente geométrica renovada por una serie de artistas -Leon Polk Smith, Ellsworth Kelly, Kenneth Noland, Frank Stella, William Scott, Jack Bush, Larry Bell, Nassos Daphnis, etcétera, que usan toda clase de nuevos materiales pictóricos creados por la química moderna y cubren la superficie con rayas y formas geométricas que crea una dimensión concreta de intenciones puristas y espaciales.

Es indiscutible que el movimiento más radical y definitivo sigue siendo el de los artistas que se han detenido en el Monocromo. Son los pintores que se han distinguido por su preocupación filosófica y artística más que estetizante los que llevaron la pintura, nuevamente, al silencio pictórico, la nada o el todo, uniendo el extremo último del círculo al iniciado por Malevich y su desierto monocromático. Sin que esto constituya una clara intención diluyeron la pintura en el muro del edificio, es decir, la integraron nuevamente en la arquitectura.

Un espacialismo cromático y mfstico cubre de lado a lado las telas de Mark Rothko con la intención de alcanzar la paz absoluta por medio del calor fuertemente difundido. Barnett Newmann restringe el elemento formal a una línea sabiamente colocada con la cual divide en dos los campos de color.

Ives Klein "Ives Le Monochrome" es quizá, el más consecuente de todos. Considera sus lienzos uniformes, cubiertos totalmente de color azul, como obras de sensibilidad absoluta, es decir, como "pintura" y "arte". Para este gran rebelde, desaparecido en plena juventud, el hombre no llegará a captar el espacio por medio de conquistas físicas, técnicas y materiales, sino a través de su "verdadera capacidad de acción extra-dimensional" basada en la sensibilidad.

El austriaco Arnulf Rainer re-cubre sus propias obras expresivas con un solo color -el negro- para crear, de este modo, un nuevo misterio dentro de la pintura y destacar así el sentido ético. También el triunfo de la ética sobre la estética es la preocupación del "hartista" alemánmexicano Mathías Goeritz, autor de ambientes metacromáticos con los cuales niega la existencia de un arte sin base espiritual. Las cruces monocromáticas que llevaron al norteamericano Ad Reinhardt, muerto también recientemente, al mismo silencio pictórico, muestran por otra parte el fin de la pintura desde el mismo punto de vista de Malevich, 
pero enriquecido con el injerto de un cierto humor que es típico para el arte después de Dada. Reinhardt sabiamente comentó: El solo objeto de cien años de arte moderno es el darse cuenta del arte en si, del arte preocupado por su propio proceso y medio, con su propia identidad $y$ distinción, arte relacionado con su única declaracion, arte consciente de su propia evolución, historia y destino, hacia su propia libertad, su propia dignidad, su propia esencia, su propia razón, su propia moralidad y su propia conciencia. El arte no necesita los significados de "realismo" o "naturalismo", "regionalismo" o "nacionalismo", "individualismo" o "socialismo" o "misticismo" o de otras ideas. ${ }^{1}$

El inquieto Lucio Fontana al cortar con un cuchillo la tela o abrirle un agujero ha asesinado al cuadro de caballete porque ha insertado la pintura en la búsqueda espacial que ya la superficie de un lienzo parece haber agotado a lo largo de su historia. Actualmente los cuadros colgados más interesantes son aquellos que crecen, se lanzan al espacio y se ligan a las artes tridimensionales, pero que dejan de ser pinturas en el sentido tradicional.

Es otro fenómeno indiscutible que la pintura, junto con la fotografía son las dos ramas que se han convertido en arte popular al divulgarse tremendamente y asi, al lado de las miles de personas que practican todas las técnicas imaginables encontramos a los hacedores de la buena pintura que, aislados en una torre de marfil, siguen produciendo obras monopolizadas por museos, galerías y coleccionistas. Los esfuerzos y la trascendencia de la pintura en la actualidad, además de constituir un mercado y un lujo dentro de la política de los países, está en ser la inspiradora del mundo del diseño: telas, tapices, tipografía, productos industriales en general, etcétera, y es, fundamentalmente en los usos aplicados a la industria y la tecnología donde tiene una fuerte repercusión en la vida. Hoy vemos jóvenes vestidas de Op o Pop Art, coches sicodélicos, linóleums mondrianescos o escenografías tachistas.

No cabe duda que la pintura de los últimos cien años fruto de una preocupación eminentemente estetizante y decorativa ha dado muestras de una riqueza formal nunca antes lograda, pero no ha podido fundirse con la vida. Es una verdad que con las antiguas categorías artísticas, con las reglas, divisiones y cánones de las Bellas Artes no podemos juzgar el arte de nuestro tiempo. Desgraciadamente, parece que todavia no estamos suficientemente equipados para dar validez artística a otros fenómenos

1 Reinhardt, Ad en Americans 1963. The Museum of Modern Art, New York, 1963. pp. 82 a 86 . 
que invaden nuestros sentidos en el complejo urbano porque una tradición que aún pesa demasiado sobre el crítico y el público en general no los consideran como pertenecientes al mundo del arte. Es, hasta tiempos muy recientes y a pesar de la carga exitosa que respalda a los pintores, cuando se empieza a entender que no es, en la actualidad el cuadro el que pueda contener con mayor autenticidad y plenitud la carga espiritual del hombre contemporáneo. 